\title{
LOS MECANISMOS DE DEMOCRACIA DIRECTA EN EL CONSTITUCIONALISMO LATINOAMERICANO: EL CASO DE NICARAGUA
}

\author{
Direct democracy mechanisms in the latin american \\ constitutionalism: the case of Nicaragua
}

\section{Edwin Ramón CASTRo RIVERA*}

\begin{abstract}
Sumario:
Introducción I. Preguntas claves II. La construcción de nuevos paradigmas III. La democracia moderna III.1. La democracia como concepto dinámico III.2. Los conceptos de democracia representativa y participativa III.3. Manifestaciones del concepto de democracia directa III.4. Las formas limitativas del concepto de democracia representativa III.5. Democracia y división de poderes IV. Crisis de los regímenes democráticos representativos $V$. Mecanismos de democracia directa en los regímenes políticos latinoamericanos V.1 Los mecanismos de democracia directa como una alternativa a la crisis V.2. Los MDD en el constitucionalismo latinoamericano VI. La democracia en Nicaragua VI.1. Los modelos democráticos en el constitucionalismo nicaragüense VI.2. Los MDD en la vigente Constitución. Resultados y Aportes. Lista de referencias
\end{abstract}

Resumen: Los regímenes democráticos modernos surgidos a partir de la ilustración nacen con la contradicción intrínseca de si lo que debe aplicarse es la democracia directa o una democracia representativa. La práctica determinó la imposición de la democracia representativa. La democracia representativa ha experimentado cambios importantes en cuanto a su concepción, sujetos, alcance $y$ límites; en las últimas décadas del siglo pasado se hizo evidente una suerte de crisis de los sistemas democráticos representativos, dando lugar al surgimiento de mecanismos de democracia directa y mecanismos de democracia participativa, especialmente en el constitucionalismo latinoamericano. En la inmensa mayoría de las constituciones latinoamericanas encontramos mecanismos de democracia directa que van, desde los tradicionales plebiscitos y referéndum, hasta novedosas e innovadoras formas participativas. En el constitucionalismo nicaragüense, a partir de la Constitución de 1824, se constata un desarrollo progresivo que permite hablar de una democracia de propietarios, democracia con exclusión de la participación de las mujeres, democracia con segregación racial, hasta la democracia con sufragio universal. Es en la Constitución de 1987 donde comienzan a manifestarse mecanismos de democracia directa, que luego se profundizan en las sucesivas reformas producidas hasta hoy. Se habla pues de una democracia representativa, participativa y directa, con participación protagónica del individuo, familia y comunidad, y con un Modelo de Alianza, Dialogo y Consenso entre empresariado, trabajadores y Gobierno, para el desarrollo económico y social del país; lo que, al igual que ha ocurrido en distintos países latinoamericanos, ha dado lugar al establecimiento normativo de mecanismos de democracia directa, como el plebiscito, referéndum, consultas populares, revocación de mandato, control social, presupuesto participativo, participación protagónica y decisoria en la elaboración, gestión y control de politicas nacionales y locales, cabildos municipales, asambleas o consejos locales y sectoriales.

* Profesor de Derecho Constitucional de la Universidad Centroamericana (UCA) y Profesor de Derecho Constitucional e Investigador del Instituto de Estudio e Investigación Jurídica (INEJ), Nicaragua. Doctor en Derecho por la Universidad Centroamericana (UCA). 
Palabras claves: Democracia Representativa, Participativa y Directa; Mecanismos de Democracia Directa

Abstract: Modern democratic regimes arising from the illustration were created with an intrinsic contradiction on whether what they need to exercise is direct democracy or representative democracy. The exercising government determined the imposition of representative democracy. Representative democracy has experienced major changes in its conception, subject, scope and limits; in the last decades of the last century was evident a sort of crisis of the democratic representative systems, resulting in the emergence of mechanisms of direct democracy and mechanisms of participatory democracy, especially in Latin American constitutionalism. In the vast majority of Latin American constitutions we find mechanisms of direct democracy that van, from the traditional referendums and referendum, to new and innovative participatory forms. Nicaraguan Constitutions, from the Constitution of 1824, notes a progressive development that allows to speak of a democracy of owners, democracy with exclusion of women's participation, democracy with racial segregation, until democracy with universal suffrage. It is in the 1987 Constitution where begin to develop mechanisms of direct democracy, which then delve into successive reforms produced until today. Discussed as a representative, participatory democracy and direct, with active participation of the individual, family and community, and a model of partnership, dialogue and consensus among business, workers and Government, to the economic and social development of the country; What, as has happened in various Latin American countries, for different participatory forms including the plebiscite, referendum, public consultation, recall election, social control, participatory budget, protagonist and decision-making powers when creating, managing, and controlling local and national policies, municipal councils, local and regional convention and councils.

Key words: Representative, Participatory, and Direct Democracy; Direct Democracy Mechanisms

\section{Introducción}

En este artículo de investigación nos ocupamos de analizar y reflexionar acerca de la validez, sustento y legitimidad del tipo de democracia imperante en esta segunda década del siglo XXI. Estudiamos el fenómeno de la convivencia y coexistencia de distintos modelos de democracia, la representativa, participativa y democracia directa, en especial en los regímenes democráticos latinoamericanos que han desarrollado nuevos enfoques y paradigmas, y su desarrollo en Nicaragua.

Es en la crisis existente en los regímenes democráticos que se plantea esta investigación, con el objetivo de analizar la necesidad y la posibilidad de la existencia de mecanismos de democracia directa en los ordenamientos jurídicos en esta segunda década del siglo XXI, y que ellos vengan a fortalecer la democracia. Pretendemos con ello aportar a la construcción de nuevos paradigmas de democracia, tanto en su concepción, sujetos, alcance y límites.

Finalizada la Segunda GuerraMundial, comienzan algunos países a adoptarla consulta popular directa de tipo refrendario (Bélgica, Francia, Italia). A partir de la década de los 60 del siglo pasado se produce un verdadero brote de institutos de democracia directa en Europa, incorporándolo en sus ordenamientos jurídicos incluyendo a Inglaterra, que organizó varios referéndum a partir de $1975^{1}$.

El surgimiento de estos mecanismos de democracia directa en la actualidad, se asienta en una crisis de la democraciarepresentativa, enel incremento de la desconfianza de los y las ciu-

1 Hernández VAlle, Rubén (2002), “De la democracia Representativa a la Democracia Participativa”, en: Anuario Iberoamericano de Justicia Constitucional, núm. 6, pp. 199-219. 
dadanas en la política expresada en la baja participación electoral ${ }^{2}$ y en constantes manifestaciones de protestas y revueltas sociales contra gobiernos representativos incapaces de gestionar la crisis sistemática actual ${ }^{3}$, o el cambio de época, como afirma Subirats ${ }^{4}$.

Este cambio de época debe provocar, y lo está provocando, una discusión entre democracia representativa y democracia directa, en cómo avanzamos a una democracia que no es minimalista, que no es sólo reglas, sino también, valores 5 .

En todos los países de América Latina existen mecanismos de consulta popular con variadas concepciones vinculantes, más allá de los referendos o plebiscitos. En las últimas décadas nuevos y viejos mecanismos de democracia directa han comenzado a ocupar lugares relevantes en la agenda política, incorporándolos en las Constituciones, Leyes y prácticas en América Latina ${ }^{6}$.

Dicha ola de experiencia democrática en América Latina ha ido de la mano de una cada vez más abundante literatura académica que, desde diversas disciplinas y pareceres, sugiere perspectivas teóricas y analíticas innovadoras para el análisis de las tensiones específicas de los diferentes mecanismos participativos y sus contribuciones al fortalecimiento del proceso democrático en la región.

Tradicionalmente, buena parte de las formas democráticas contemporáneas han sido concebidas en Europa y América del Norte y luego, transportadas al resto del mundo. Hoy estamos asistiendo a un momento en el que, quizás por primera vez en la historia democrática moderna, las vías de institucionalización democrática remozadas, renovadas y revitalizadas, se han direccionado del Sur al Norte, haciendo a los presupuestos participativos latinoamericanos, un modelo comúnmente importado por las viejas democracias de Europa y Norte América. Las carabelas están retornando, se afirma.

Para apoyar este análisis, utilizamos Derecho comparado en diecinueve países de Latinoamérica, en la praxis normativa constitucional y legal sobre el tema.

Analizamos la democracia en Nicaragua, para ver su posición normativa en la historia constitucional con relación a elementos de democracia y determinamos las manifestaciones de democracia directa en la Constitución vigente.

Ambas manifestaciones democráticas, la democracia directa y la democracia representativa, no sólo pueden, sino que además deben, coexistir para fortalecer la democracia en el siglo XXI, es la hipótesis de esta investigación.

Consideramos que no se pretende que un modelo de democracia directa se venga a imponer bruscamente, rompiendo con el modelo existente de democracia representativa, sino, partir de la democracia que tenemos, para llegar a la democracia que queremos. En este contexto, donde se está escribiendo un nuevo constitucionalismo, sobretodo en América Latina, es que inscribe este trabajo investigativo.

\footnotetext{
${ }^{2}$ Secretaría Nacional de Planificación y Desarrollo (2011), Tendencias de participación ciudadana en Ecuador, SENPLADES, Quito.

3 Welp, Yanina (2008), "Participación ciudadana y nuevas tecnologías en América Latina”, En A. Lissidini, Y. Welp \& D. Zovatto (coords.), Democracia directa en Latinoamérica, Prometeo Libros, Buenos Aires, pp. 71-96.

4 Subirat Humet, Joan (2012), Parlamento y políticas públicas. Conferencia magistral en la Maestría de Derecho Parlamentario realizada en el salón Rubén Dario de la Asamblea Nacional de Nicaragua. Managua, 25 de julio.

5 Idem.

${ }^{6}$ Welp. Yanina, op. cit. nota 3.
} 


\section{Preguntas clave}

En el desarrollo de la investigación se trata de dar respuesta a un sinnúmero de preguntas que, a mi juicio, resultan relevantes, así: ¿Cuáles son esos nuevos enfoques que el constitucionalismo latinoamericano está planteando? ¿Es posible la existencia de mecanismos de democracia directa en regímenes de democracia representativa? ¿Los mecanismos de democracia directa estorban o fortalecen la democracia? ¿Cuáles son esos mecanismos de democracia directa y de democracia participativa? ¿Estaremos ante un nuevo enfoque paradigmático en la conformación del Estado?

La investigación se enmarca en esta época de globalización, en un mundo tecnológicamente globalizado, donde nos desplazamos de un mundo de certezas hacia un mundo de nuevos e inciertos desafíos. En la actualidad, estamos llegando a un concepto diferente de la realidad, el concepto de un mundo en construcción y cambios permanentes. Esta nueva concepción del mundo y de la realidad nos genera más inseguridades, donde lo único cierto es lo incierto, la razón no está obligadamente asociada a la certeza, pero tampoco a la ignorancia, hay una búsqueda constante de la verdad, de verdades conceptuales, o al menos, una aproximación de la misma. El concepto de un mundo en construcción y cambio permanente afecta todos los ámbitos del saber, de las ciencias en general y de las ciencias sociales en particular, de ahí que el ámbito del Derecho y la democracia como forma de gobierno se encuentren también inmersos en este proceso de constante revisión y adaptación.

\section{La construcción de nuevos paradigmas}

Este artículo sigue la idea de que es necesario revolucionar el pensamiento y cambiar de un pensamiento lineal a un pensamiento complejo. Revolucionar el pensamiento no es desechar lo existente para instalar uno nuevo, sino que sobre el existente se debe ir construyendo el nuevo, construyendo nuevos paradigmas jurídicos, nuevos paradigmas de democracia. La complejidad aparece allí donde el pensamiento simplificador falla, pero no lo destruye, sino que lo integra para poner orden a los fenómenos, descartando lo incierto, quitar ambigüedades, clarificar, distinguir, jerarquizar; sólo la complejidad nos puede llevar a la correcta apreciación y análisis de los fenómenos. La realidad de los fenómenos se debe estudiar de una forma compleja, en su estado caótico, no desde una simplificación?.

No estamos en una época de cambio, sino en un cambio de época, donde es evidente la construcción de nuevos paradigmas; estamos en un cambio de primera magnitud que se está dando en muchos órdenes de carácter social y que tiene amplias implicaciones desde el punto de vista político y jurídico, la democracia, desde su concepción y su praxis, sufre también nuevas y renovadas transformaciones, este cambio de época debe provocar, y está provocando, una discusión entre la democracia directa, la democracia participativa y la democracia representativa; de manera pues que podemos afirmar que nos enrumbamos a una democracia que no es minimalista ${ }^{8}$, una democracia que no es simplemente electoral, que no es sólo reglas, sino una democracia centrada también en valores y vivencias.

\footnotetext{
7 Morín, Edgar (1990), Introducción al pensamiento complejo, Gedisa, Barcelona.

8 Boвbio, Norberto (1986), El futuro de la democracia, Fondo de Cultura Económica, México. 


\section{La democracia moderna}

\section{III.1. La democracia como concepto dinámico}

El concepto de democracia ha tenido una diversidad de criterios históricos cambiantes desde la génesis del Estado Constitucional Moderno en el siglo XVIII hasta la segunda década del siglo XXI; dichos términos no están universalmente unificados ni en sus conceptos, ni en sus contenidos, ni en sus alcances, ni en sus límites, proliferando una variedad de criterios. La democracia es un concepto que ha variado y cambiado en el transcurso del tiempo, y tiene diversas aplicaciones de conformidad a la realidad política concreta.

Tratar de conceptualizar la democracia hoy en día, siendo un término jurídico comúnmente utilizado, y que está tanto en el imaginario de la academia, como en el imaginario popular, con diversas acepciones, alcances y límites, pareciera ser una tarea difícil, pues es un concepto que se ha transformado con el curso del tiempo. El concepto actual de democracia no es un concepto cerrado, acabado, es un concepto en transformación evolutiva, partiendo desde la Ilustración hasta nuestros días, asumiendo elementos grecorromanos de la antigüedad y elementos cristianos del Medioevo.

La dificultad de arribar a una única definición del concepto y a un reconocimiento inequívoco de los atributos de la democracia nos obliga a un análisis conceptual-histórico y a una descomposición analítica de la palabra democracia, en sus fundamentos, sus contenidos, sus alcances y sus límites ${ }^{9}$.

Sin querer ahondar en la concepción clásica del concepto de democracia, quisiéramos recordar la referencia que sobre ella hace Aristóteles en la Grecia Clásica, cuando afirma:

La primera forma de democracia es la que se funda principalmente en la igualdad. Y la ley de tal democracia entiende por igualdad que no sean más en nada los pobres que los ricos, que ni dominen los unos sobre los otros, sino que ambas clases sean semejantes. Pues si la libertad, como suponen algunos, se da principalmente en la democracia, y la igualdad también, esto podrá realizarse mejor si todos participan del gobierno por igual y en la mayor medida posible. Y como el pueblo constituye el mayor número y prevalece la decisión del pueblo, este régimen es forzosamente una democracia ${ }^{10}$.

Cabe destacar que, en los tiempos en que Aristóteles trataba de conceptualizar lo que debería ser un régimen democrático, sólo se reconocían los derechos ciudadanos a los hombres libres por nacimiento; las mujeres, los esclavos, los mercaderes extranjeros, no eran considerados ciudadanos y, en consecuencia, no ejercían derechos políticos; era una minoría de la población estimada en no más de un doce a un quince por ciento, a los que se les reconocían derechos y ejercicios políticos.

Esta democracia, era ejercida por la asamblea de ciudadanos en el ágora ateniense en la época de Pericles y en las polis romanas, donde expresaba la voluntad directa de los ciudada-

\footnotetext{
9 Murray, Santiago (2013), "La Democracia Representativa en el Sistema Interamericano", en: Democracia y representación en el Umbral del Siglo XXI. Memoria del III Congreso Internacional de Derecho Electoral, [en línea], disponible en: http://www.bibliojuridica.org/libros/1/238/23.pdf, [consultado el 23 de mayo de 2013].

10 Aristóteles (2005), Política, traducción de Julián Marías y María Araujo, Centro de Estudios Políticos y Constitucionales, Madrid, p. 175 .
} 
nos, cuyo número, nunca sobrepasó de las dos mil personas, constituyendo una minoría de la población ${ }^{11}$, y desconocían el principio de soberanía popular.

El objeto de traer a colación esta referencia de Aristóteles, es para dejar plasmado elementos conceptuales que hoy siguen siendo válidos y valiosos, tales como: la libertad, la igualdad, la participación de todos y la decisión de la mayoría.

Otro momento de duda en el análisis conceptual de la democracia moderna, dentro de la elaboración de este trabajo investigativo, es dónde se encuentra su génesis. La democracia basada en la soberanía popular, objeto de estudio de esta investigación y particularmente de este capítulo, parte de la premisa siguiente: ¿se debe partir su análisis histórico desde la ilustración, a sabiendas que la democracia no era universal, ya que las mujeres no ejercían sus derechos políticos? o ¿debemos hablar que la democracia en nuestros días nace en Nueva Zelanda en 1893 , al concedérsele por primera vez en la historia el derecho al voto a las mujeres y a la minoría del pueblo originario maorí? ${ }^{12}$

Nos sumamos a las corrientes doctrinarias mayoritarias que ubican el punto de inflexión histórico de la democracia en la ilustración, partiendo del cambio esencial conceptual de la soberanía que la sustenta, es la soberanía basada en el pueblo, y los otros fenómenos no menos importantes serán vistos como parte de los cambios, y por qué no decir evolución de la concepción democrática y aplicación en los regímenes considerados demócratas.

La democracia debe ser vista como una inmensa experiencia humana, relacionada a la búsqueda histórica de libertad, justicia, y bienestar material y espiritual, es una experiencia evolutiva permanentemente en construcción e inconclusa, teniendo siempre presente sus tensiones, sus límites, sus incumplimientos, sus denigraciones. Se ha convertido en un símbolo de libertad y justicia; es a la vez, un fin y un mecanismo, un procedimiento para el acceso y el ejercicio del poder de los hombres y mujeres, pero a su vez, es una manera de construir, garantizar y expandir la libertad, la justicia, el progreso, es decir, el buen vivir, tratando de organizar las tensiones y conflictos de la sociedad.

La democracia debe ser vista desde dos concepciones principales: democracia como forma de gobierno y democracia como forma de vida; la primera determina un gobierno que obtiene su autoridad y poder político del pueblo, pero la democracia como forma de gobierno está inmersa dentro de una concepción más amplia, que es la democracia como forma de vida, involucrando a toda organización humana y no limitándola exclusivamente al gobierno, sino desde el Estado hacia la sociedad misma y viceversa. Pero la democracia también es procedimental, de normas y reglas, y es una democracia sustantiva, consistente en medidas y políticas, de acuerdo a la voluntad popular, la igualdad de oportunidades y el respeto de las libertades de la población. La democracia tiene un valor procedimental y otro sustancial, donde el pueblo puede decidir su destino de acuerdo con las reglas del juego democrático que él mismo establece en las decisiones colectivas. Un análisis sistémico nos plantea que la democracia tiene tres dimensiones: un control popular, una igualdad política y una dimensión de estabilidad o de eficiencia de los resultados de la democracia.

La riqueza de esta discusión es innegable y nos demuestra un interés expreso en el mundo actual y, en particular, en América Latina; pero no es menos cierto que la variedad del uso del término democracia complica o, a veces, ofusca el mismo debate, consideramos que se debe continuar la discusión encaminada a aclarar el concepto de democracia, estableciendo en lo

\footnotetext{
${ }^{11}$ Murray, Santiago, op. cit. nota 9.

${ }^{12}$ Carpizo, Jorge (2007), “Concepto de democracia y sistema de gobierno en América Latina”, en: Boletín Mexicano de Derecho Comparado, Instituto de Investigaciones Jurídicas de la UNAM, nueva serie, año XL, núm.119, pp. 325-384.
} 
posible, consensos acerca de su significado, alcances y estándares en este siglo XXI, es decir, sin pretender ser absolutos, la construcción conceptual de un nuevo paradigma de democracia. Paradigma que se ha manifestado y se manifiesta en diferentes formas: democracia representativa, democracia participativa y democracia directa.

Para este trabajo investigativo, he tratado de conceptualizar democracia representativa, democracia participativa y democracia directa, sin pretender aportar un axioma acabado, pero sí una necesaria y obligatoria aproximación en la elaboración de este artículo.

\section{III.2. Los conceptos de democracia representativa y participativa}

La democracia representativa o democracia electoral es una forma de gobierno caracterizada por el rol de las elecciones como único fenómeno del ejercicio democrático, cuidando claramente la calidad de las mismas, que deben ser sin violencia, sin fraude, sin chantajes, sin prebendas, sin presiones, sin proscripciones, sin exclusiones y sin límites de ninguna naturaleza. Este tipo de democracia electoral representativa está cimentada, fundamentalmente, en el sufragio libre, universal, transparente, informado, con amplio respeto a los derechos políticos de los ciudadanos, correspondiendo a una concepción procedimental que Bobbio ${ }^{13}$ denominó democracia minimalista, refiriéndose a las condiciones mínimas indispensables para el ejercicio democrático. El ejercicio del gobierno se realiza a través de los representantes electos por los ciudadanos, siendo la participación de estos últimos únicamente en los sufragios. Este tipo de régimen democrático se volvió el clásico en los siglos XVIII, XIX y XX, y sobrevive hasta nuestros días, sufriendo desde finales del siglo pasado y en la actualidad, duras críticas por sus objetivos incumplidos y consecuencia de ellos son los cambios que en la actualidad se proponen.

El concepto de democracia participativa, dotado de sustantividad propia, aparece en el campo del Derecho Constitucional y de la ciencia política en la segunda mitad del siglo XX; surge del seno de la misma democracia representativa, que da lugar a presiones populares para cambios políticos, conllevando el nacimiento de la democracia participativa, tal y como se entiende en la actualidad; sin embargo, no podemos negar que tiene su antecedente inmediato en la democracia directa. La democracia participativa se afirma en la actualidad como un modo de moderación y control sobre los representantes, que se materializa a través de comunidades organizadas, quienes intentan influir de diversas formas para que una determinada política pública sea adoptada o no; presupone un proceso de crecimiento de la responsabilidad política de la población, en la medida en que ésta participa e influye en las decisiones que afecta el modus vivendi.

No existe igualdad de criterios cuando se habla del concepto de democracia, tampoco de su contenido y alcance, pero podemos extraer elementos comunes dentro de la diversidad conceptual: la democracia participativa nace de las entrañas de la democracia representativa y sólo dentro de ella puede desarrollarse; surge como mecanismo de rescate a una criticada y deteriorada democracia representativa; la participación del ciudadano es eventual y puntual y se establece con mayor determinación como una participación consultiva; las decisiones permanentes y constantes de gobierno son tomadas por los representantes debidamente elegidos; los ciudadanos son gobernados por personas seleccionadas mediante sufragio, participando organizadamente para influir con sus criterios en la toma de decisiones. Se entiende que en la democracia participativa las decisiones en última instancia son tomadas por los representantes elegidos democráticamente, mismas que son influenciadas por los electores organizados a través de diversas maneras.

$\overline{{ }^{13} \text { BoввIO, Norberto, op. cit. nota } 8 .}$ 


\section{III.3. Manifestaciones del concepto de democracia directa}

En el siglo XX, después de la Segunda Guerra Mundial, aparece en el texto de la Declaración Universal de los Derechos Humanos del 10 de diciembre de 1948 que toda persona tiene derecho a participar en el gobierno de su país, directa o por medio de sus representantes libremente elegidos. Si bien es cierto que el concepto de democracia directa se remonta desde la antigüedad en las civitas griegas, donde los ciudadanos reunidos en las ágoras tomaban directamente las decisiones del gobierno, con la aclaración innecesaria de que los ciudadanos escasamente sobrepasaban el diez por ciento de la población, debido a que no eran ciudadanos ni las mujeres, ni los comerciantes, ni los extranjeros, ni los esclavos.

En la Ilustración, Rousseau ${ }^{14}$ planteaba que la única forma de ejercer la democracia era de forma directa, sustentada en la soberanía popular, siendo la única liberadora al manifestar que pobrecitos los ingleses que se creen libres porque votan por sus representantes, mas no saben que son verdaderos esclavos entre elección y elección.

A finales del siglo XIX e inicios del XX, Jellinek ${ }^{15}$ expresaba que la democracia directa se manifiesta dentro de la democracia representativa en Estados donde se ha dado una democratización progresiva de la sociedad y existen instituciones que alcanzan reconocimiento constitucional que incluyen la participación directa del pueblo en el Poder Público.

La democracia directa en estos días, vista dentro de regímenes democráticos representativos y no como elemento sustitutivo de la misma, no tiene una concepción de uniformidad universal, pero presenta elementos más o menos comunes dentro de esa diversidad de criterio: la democracia directa en la actualidad, o más específicamente los mecanismos de democracia directa, se presentan como un avance evolutivo de la democracia participativa; no tiene como objetivo fundamental inmediato sustituir el régimen democrático representativo por uno basado exclusivamente en democracia directa; busca que la intervención de los ciudadanos en la Política Pública sea constante, sectorial y territorialmente, y no puntual y eventual, ni simplemente consultiva, sin que los funcionarios pierdan sus responsabilidades ejecutivas de dichas políticas, ni de la realización de las mismas; deben crearse e institucionalizarse cada día más mecanismos de democracia directa que conlleven a la participación protagónica y decisoria del cuerpo organizado; tiene como objetivo actual el fortalecimiento y la revitalización de la democracia misma.

Como concepto en esta investigación, se entiende por democracia directa en la actualidad, aquélla en la que las decisiones son tomadas por las y los ciudadanos, acompañados de los representantes electos democráticamente, siendo estos últimos los que mantienen la responsabilidad de la ejecución de las medidas, bajo la auditoría de los primeros, a través de diversos mecanismos o formas de organización.

En la actualidad, se conceptualizan mecanismos de democracia directa y mecanismos de democracia participativa, la diferencia entre ambos es objeto de discusión conceptual, porque ella no estriba en el tipo de mecanismo, sino en la capacidad decisoria de la participación de la población. El plebiscito y el referéndum parecieran ser los mecanismos más tradicionales de la democracia directa, sin embargo, si el resultado de ellos no es de vinculación obligatoria y son simplemente consultivos, son mecanismos de democracia participativa; y por otro lado, las asambleas, consejos o gabinetes sectoriales o territoriales parecieran ser mecanismos de democracia participativa, no obstante, si en ellos las decisiones las toman los representantes de la población, son mecanismos de democracia directa; en estos casos, estos representantes no

\footnotetext{
${ }^{14}$ Rousseau, Jean-Jacques (1992), El Contrato Social, Editorial Guaymura, Tegucigalpa.

15 JellineK, Georg (1991), Reforma y mutación de la Constitución, Centro de Estudios Constitucionales, Madrid. 
son permanentes, ni adquieren voluntad decisoria propia, a diferencia de los representantes de la democracia representativa.

Es innegable que la democracia moderna nace con fuertes contradicciones, entre la democracia representativa y la democracia directa, contradicción histórica que se resuelve en la práctica a favor de la democracia representativa, asumiéndose a partir del siglo XVIII como la única democracia real posible a ser implementada, la única manera viable para el ejercicio del gobierno democrático era el régimen representativo, pese a la oposición de Rousseau que planteaba que un pueblo que se da representantes, deja de ser libre y deja de ser democrático.

Lo que se imponen los gobiernos democráticos, muy a pesar de los postulados rousseaunianos, es el régimen democrático representativo, soportado en la soberanía popular que se ejerce fenoménicamente en las elecciones de sus representantes. La democracia representativa es la que va a imperar en los regímenes políticos hasta nuestros días, pero con diversos cambios históricos, ya que en su nacimiento, dicha democracia no era general, ni universal.

\section{III.4. Las formas limitativas del concepto de democracia representativa}

La democracia moderna comenzó como una democracia excluyente, donde tenían capacidad de ejercicio político solamente los varones dueños de propiedad y capital, argumentándose que lo contrario iría en contra de la eficiencia de la misma democracia, que sólo la propiedad hace a los hombres capaces para el ejercicio de los derechos políticos. Ésta es la democracia de los regímenes políticos de los siglos XVIII y XIX, situación que va a cambiar en la segunda mitad de dicho siglo con nuevos pensadores y nuevos fenómenos políticos, encontrándonos al albor del siglo XX, eliminado en casi todas las democracias del mundo las restricciones políticas censitarias y de capacidad económica, terminando la diferencia política entre propietarios y trabajadores, estableciéndose, al menos en la teoría jurídica, que todos los ciudadanos son iguales, independientemente de su capacidad patrimonial.

La mitad de la población, las mujeres, fueron impedidas de tener derechos políticos, desde el nacimiento de la democracia moderna y durante los siglos XVIII, XIX y parte del siglo XX. Se argumentaba que las mujeres, como los niños, no tenían voluntad política independiente, no tenían voluntad propia, pues o dependían del padre, o dependían del marido, y darles el voto significaba duplicar el voto de los maridos o el voto de los padres, sus intereses eran representados a través de una conexión tutelar, en vez de electoral.

Fue en 1893 cuando en Nueva Zelanda, se le concede por primera vez a las mujeres el derecho al voto, seguido de Australia en 1901 y Finlandia en 1906, iniciándose un nuevo paradigma de democracia representativa, y es después de la Segunda Guerra Mundial que se universaliza en todos los regímenes democráticos del mundo la participación de este derecho político a las mujeres.

Es a partir de finales de la primera mitad del siglo XX que comenzamos a ver una democracia representativa más universal, donde se van superando las exclusiones de los no propietarios, igualando el valor del voto entre propietario y no propietario, y la participación plena de las mujeres en los textos constitucionales de los Estados Democráticos Modernos.

La democracia moderna nace sin resolver la discriminación racial. La Revolución Francesa no condujo a la evolución contra la esclavitud negra en la Europa Liberal del siglo XVIII, y los escritos de Olympe De Gouges, Reflexiones sobre los Hombres Negros en 1788y El Mercado de los Negros en 1790, lo evidencian.

A lo largo del siglo XX, superada la discriminación del sufragio a los no propietarios y a las mujeres, todavía se presentan con crueles manifestaciones las discriminaciones raciales en el 
ejercicio de los derechos políticos en diversas partes del planeta. En Estados Unidos, aunque abolida la esclavitud en 1865, hasta 1970 se vivió uno de los períodos de mayor racismo institucionalizado, donde se crea un sistema de segregación racial, utilizando el concepto de separados, pero iguales, que restringía los derechos políticos a la población negra. La segregación racial en Los Estados Unidos de Norteamérica era un verdadero Apartheid en Occidente, ya que el concepto concreta la separación y restricción de derechos, aislando a un ser dentro de la lógica de separados, pero iguales que corrompe a la misma dignidad humana. La discriminación racial como restricción de derechos políticos y sociales tuvo como última manifestación hasta finales del siglo XX en el régimen del Apartheid en Sudáfrica, sistema que sucumbe en 1994 con las primeras elecciones verdaderamente generales, cuando es electo un negro en la Presidencia de dicho país, Nelson Mandela y la población negra ejerce su derecho a elegir y ser electo.

A finales del siglo XX y en el siglo XXI pareciera ser que la participación democrática de las minorías étnicas fue ganando cada día más reconocimiento y respeto, lo que conllevó a la elección del primer Presidente negro, Barack Hussein Obama II, y Hillary Clinton compitió para ser elegida en noviembre del 2016 como la primera mujer Presidenta de los Estados Unidos de América, aunque perdió. A pesar de estos avances, subsiste en el sistema político-económico de Los Estados Unidos un reduccionismo identitario y cultural de grupos etnorraciales superiores, cuyas políticas son a favor de los blancos y no de toda la nación, incluyendo a las minorías que siguen siendo discriminadas y perseguidas, basta ver recientemente los asesinatos de negros a manos de la policía blanca, la persecución migratoria contra chicanos y la discriminación laboral y social hacia las minorías étnicas, lo que se evidencia en las declaraciones del actual Presidente de USA, Donald Trump.

\section{III.5. Democracia y división de poderes}

Un elemento que pareciera consustancial de la democracia clásica moderna, la democracia representativa, es la Teoría de la División de Poderes en los regímenes democráticos iniciada por John Locke, en su obra Ensayo sobre el Gobierno Civil ${ }^{16}$,continuada y desarrollada por Montesquieu en El Espíritu de las Leyes ${ }^{17}$; división a la cual Rousseau, en El Contrato Social ${ }^{18}$, se opuso desde el inicio de la democracia moderna, planteando que los políticos, al no poder dividir la soberanía en principio, la dividen en sus fines y sus objetivos: en Poder Legislativo, en Poder Ejecutivo, en Derecho de Impuestos, de Justicia y de Guerra, en Administración Interior y en el poder de negociar con extranjeros, y tan pronto, confunden estas partes cuando las separan.

Sin embargo, la Teoría de División de Poderes fue asumida como parte de la misma democracia y plasmada en el artículo 16 de la Declaración de Derechos del Hombre y el Ciudadano, del 26 de agosto de 1789 en la Revolución Francesa, donde se establece que una sociedad donde no esté establecida la garantía de los derechos, ni determinada la separación de los Poderes, carece de Constitución.

La mayoría de las últimas Constituciones emitidas en América Latina no se ciñen a la clásica Teoría de la Separación de Poderes que ha servido de piedra angular a la democracia representativa, y cada vez es más común hacer referencia a funciones y a órganos de un solo Poder en el Estado Democrático, el Poder Público o el Poder Popular, partiendo de la premisa aceptada por

\footnotetext{
${ }^{16}$ Locke, John (2014), Ensayo sobre el gobierno civil, [en línea], disponible en: http://www.universidadabierta.edu. $m x /$ Biblio/L/Ensayo\%2osobre\%2oel\%2ogob\%2ocivil.html, [consultado el 14 de febrero de 2014].

${ }^{17}$ Montesquieu (1998), Del espíritu de las leyes. $12^{\circ}$ ed. Editorial Porrúa, México.

${ }^{18}$ Rousseau, Jean-Jacques, op. cit. nota 14.
} 
odos, que la soberanía, es decir, el Poder, radica en el pueblo. Con esto, no se sostiene la concentración de funciones del Poder en un solo órgano, ni mucho menos, en una sola persona, pero de ello a concluir que el Poder Soberano radicado en el pueblo se puede y se debe dividir, es en la actualidad cada vez más cuestionado.

\section{Crisis de los regímenes democráticos representativos}

En la actualidad nos enfrentamos a una evidente crisis en los regímenes democráticos en la democracia representativa, nuevos paradigmas se están formando en la concepción y praxis de la democracia, en el mundo en que vivimos. La crisis de la democracia representativa se manifiesta en el incremento de la desconfianza de las y los ciudadanos en la política, expresados en una baja participación electoral y constantes manifestaciones de protestas y revueltas sociales contra gobiernos representativos incapaces de gestionar y resolver la crisis sistémica actual, o el cambio de época. En el período 1990-2002, en los Estados Unidos, solamente el 43.3\% de la población con derecho al voto tuvo participación electoral para elegir autoridades nacionales ${ }^{19}$; en la democracia representativa actual, pareciera que el pueblo no manda, ni gobierna, ni controla nada, debido a que carece de elementos de juicio suficientes y, por tanto, carece de capacidad de controlar políticamente nada, ni a nadie; el Poder Político es asimétrico, unos mandan y otros obedecen, una parte de la sociedad política que es minoritaria dirige a las otras partes restantes que son mayoritarias; convirtiendo el régimen político democrático para beneficio de las minorías que gobiernan en nombre de las mayorías.

En la democracia minimalista electoral existen críticas y problemas en la actualidad, que reflejan la crisis de los regímenes democráticos: las campañas electorales son cada día más mercadeo de candidatos y partidos políticos, que información a la población de planes y programas de gobierno, donde el elector pueda realmente observar la defensa de sus verdaderos intereses; existe una falta de rendición de cuentas de los representantes y los partidos políticos ante el supuesto detentor de la soberanía popular, que es el pueblo.

Hay crisis y agotamiento de la forma de actuación tradicional de los partidos políticos, que no es un hecho aislado, ni interiorista, sino que tiene su impacto en la ciudadanía, en nuestra cultura política y en la propia crisis de los regímenes democráticos representativos.

Dentro de la incertidumbre y complejidad de esta época, viene asociada la inequidad cada día mayor en la distribución de las riquezas, que se han triplicado en las últimas cuatro décadas, se ha aumentado exponencialmente la pobreza y el hambre, y aunque se reafirma la necesidad de la Democracia y el Estado de Derecho, comúnmente nos preguntamos ¿qué Democracia, qué Estado de Derecho?

El desequilibrio entre el aumento de las riquezas y la depredación de la naturaleza, nos obliga a un nuevo planteamiento de nuestra cosmovisión; la madre naturaleza debe ser vista como un ser vivo, dentro de su biodiversidad, y restituirle sus derechos como tal; a la par de restituirle sus derechos a la mayoría pobre de la población del planeta, que le han sido retirados por un sistema injusto, inequitativo; injusto en la distribución de las riquezas, en la democratización del conocimiento e injusto en la aplicación de las normas constitucionales. Pareciera ser que

\footnotetext{
${ }^{19}$ Programa de las Naciones Unidas para el Desarrollo (PNUD) (2004), La democracia en América Latina. Hacia una democracia de ciudadanas y ciudadanos, Aguilar, Altea, Taurus, Alfaguara, Buenos Aires, p. 37. 
se ha creado en conflicto entre Democracia y constitucionalismo, entre participación y norma jurídica. Es evidente que estamos en presencia de una crisis en los sistemas democráticos.

Hay promesas incumplidas en la democracia ${ }^{20}$, los regímenes democráticos representativos han prometido justicia social, igualdad, bienestar, y esta democracia representativa no lo ha conseguido; la crisis, fenoménicamente hablando, de los gobiernos representativos viene desde su génesis, pero se manifiesta con mayor fuerza a principios del siglo $\mathrm{XX}$, y profundiza sus efectos a finales de dicho siglo y en la primera década del siglo XXI.

El modelo de democracia formal representativo es ineficiente; los ciudadanos no se conforman con ser simplemente convocados periódicamente para elegir a sus representantes.

\section{Mecanismos de democracia directa en los regímenes políticos latinoamericanos}

\section{V.1. Los mecanismos de democracia directa como una alternativa a la crisis}

Frente a la crisis de los regímenes democráticos representativos, se establecen mecanismos de democracia participativa y mecanismos de democracia directa como una forma de ejercer y valorar la ciudadanía, dando el paso de una democracia electoral, a una democracia de ciudadanía. En casi todos los países de América Latina, existen mecanismos de democracia participativa y mecanismos de democracia directa, con variadas concepciones vinculantes, incorporándolo en las Constituciones, normas legales, políticas nacionales y prácticas políticas. Los MDD constituyen una búsqueda de solución a la crisis de la democracia ${ }^{21}$.

A los planteamientos de la necesidad y la realidad de incorporación de mecanismos de democracia directa, se presentan voces con preocupaciones en la aplicación de dichos mecanismos, expresando que ellos pueden ser de fácil manipulación, debilitando la institucionalidad de los gobiernos representativos y consolidando gobiernos de facto, a través de consultas populares. Si bien pudieran ser ciertas estas preocupaciones en el uso de los MDD, no menos cierto es que la democracia se sustenta en la soberanía popular y que la soberanía popular tiene su expresión más íntima en los valores de las y los ciudadanos, en sus capacidades y sus decisiones.

Uno de los argumentos esgrimidos con mayor firmeza para sustentar el modelo de democracia representativa es la complejidad de los gobiernos y, sobretodo, en esta época de globalización. Una de las características de la globalización es el enorme desarrollo de los procesos de información y comunicación, las nuevas tecnologías de la información y la comunicación (TIC), que nos pone a disposición en cortísimos espacios de tiempo una vasta información y una eliminación de las distancias. Las TIC en sí mismas no vienen a mejorar la democracia, pero son instrumentos que contribuyen a facilitar la participación protagónica y decisoria de las ciudadanas y los ciudadanos en el qué hacer político, al estar informados con certeza y celeridad, y con ello, contribuyen a la búsqueda de solución de la crisis democrática establecida.

En América Latina se evidencia con mayor fortaleza un nuevo constitucionalismo que implica transformaciones en el concepto, alcance, límites, objetivos y sujetos en el paradigma democrático. Desde México hasta Argentina, se registran novedosos mecanismos de democracia directa, aunque bajo formatos disímiles, intensidades diversas y resultados heterogéneos de la participación. De diecinueve Constituciones analizadas, todas contemplan mecanismos de democracia directa, inclusive, en México existen MDD en la mayoría de las Constituciones

\footnotetext{
${ }^{20}$ BobBio, Norberto, op. cit. nota 8.

${ }^{21}$ Zovatto, Daniel (2008), "Las instituciones de democracia directa a nivel nacional en América Latina. Balance comparado: 1978-2007”, en: A. Lissidini, Y. Welp \& D. Zovatto (coords.), Democracia Directa en América Latina, Prometeo Libros, Buenos Aires, Argentina, pp. 253-296.
} 
Estatales. Los países donde existen mecanismos de democracia directa en sus normativas constitucionales son: Argentina, Bolivia, Brasil, Chile, Colombia, Costa Rica, Cuba, Ecuador, El Salvador, Guatemala, Honduras, México, Nicaragua, Panamá, Paraguay, Perú, República Dominicana, Uruguay y Venezuela.

Tabla 1. Mecanismos de Democracia Directa existentes en normativas constitucionales de países de América Latina

\begin{tabular}{|c|c|c|c|}
\hline Número & País & Año de la Constitución & Artículos relevantes \\
\hline 1 & Argentina & 1994 & 39,40 \\
\hline 2 & Bolivia & 2009 & $\begin{array}{l}1,7,11,12,26,93,157,162,170,240,241, \\
242,257,259,260,286,317 \text { y } 411\end{array}$ \\
\hline 3 & Brasil & 1988, reformas 2001 & 14,18 y 49 \\
\hline 4 & Chile & 1980, reformas 2000 & $5,32,107,117$ y 119 \\
\hline 5 & Colombia & 1991, reformas 2001 & $\begin{array}{l}3,40,57,58,59,60,67,70,103,104,105, \\
155,170,270,297,307,318,319,321,340, \\
374,376,377,378 \text { у } 379\end{array}$ \\
\hline 6 & Costa Rica & 1949, reformas 2002 & $102,105,123,124,129$ y 195 \\
\hline 7 & Cuba & 2003 & $1,2,3,68,88,90$ \\
\hline 8 & Ecuador & 2008 & $\begin{array}{l}61,95,96,97,98,99,100,101,102,103,104, \\
105,106,107,156,157,204,205,206,207, \\
208,209,275,276,278,279,283,340,341, \\
347,441,442 \text { y } 444\end{array}$ \\
\hline 9 & El Salvador & 1983, reformas 2000 & 73,89 \\
\hline 10 & Guatemala & 1985, reformas 1994 & $\begin{array}{l}173,277,280 \text {, Disposiciones Transitorias ar- } \\
\text { tículo } 19\end{array}$ \\
\hline 11 & Honduras & 1982, reformas 2005 & 2 y 5 \\
\hline 12 & México & 1917, reformas 2015 & $2^{\circ}, 6^{\circ}, 21,35,36,41,71,73,113,115$ y 122 \\
\hline 13 & Nicaragua & 1987, reformas 2014 & $\begin{array}{l}2,6,7,49,50,59,70,81,97,98,101,105,111 \\
118,140,160,166,168,173180\end{array}$ \\
\hline 14 & Panamá & 1972, reformas 2006 & $227,238,239,313,314$ y 325 \\
\hline 15 & Paraguay & 1992, reformas 2011 & $1,121,122,123,203,289$ y 290 \\
\hline 16 & Perú & 1993, reformas 2000 & $2,31,32,190$ y 206 \\
\hline 17 & $\begin{array}{c}\text { República } \\
\text { Dominicana }\end{array}$ & 2015 & $22,97,203,206$ y 272 \\
\hline 18 & Uruguay & 1967, reformas 1997 & $79,82,304,322$ y 331 \\
\hline 19 & Venezuela & 1999 & $\begin{array}{l}5,6,62,70,71,72,73,74,84,102,103,119, \\
120,121,122,123,125,127,128,184,62,143, \\
205,341,342,345,348\end{array}$ \\
\hline
\end{tabular}

Fuente: Elaboración propia a partir de Zovatto, 2008. 


\section{V.2. Los MDD en el constitucionalismo latinoamericano}

El constitucionalismo latinoamericano y los mecanismos de democracia directa, no son sino otra forma de mirar y reaccionar ente esa realidad. Los mecanismos de democracia directa que aparecen en los textos constitucionales de América Latina son:

Plebiscito y referéndum: se encuentran en las diecisiete Constituciones antes referidas, no en todas se establece con claridad la obligatoriedad de la aplicación de sus resultados -como es el caso de Cuba, Honduras y Nicaragua-; en cuatro Constituciones, como Argentina, Chile, El Salvador y Paraguay, existen, además de consultas populares vinculantes, las de carácter meramente consultivo; en las diecisiete la convocatoria a la consulta puede ser desde arriba, desde las autoridades del gobierno; y desde la población, en todas ellas, excepto: Brasil, Chile, El Salvador, Guatemala y Paraguay.

Iniciativa Legislativa Popular: este MDD se contempla en catorce Constituciones de América Latina, a saber: Argentina, Bolivia, Brasil, Colombia, Costa Rica, Cuba, Ecuador, Guatemala, México, Nicaragua, Paraguay, Perú, Uruguay y Venezuela. La iniciativa legislativa popular (ILP) está referida únicamente a leyes ordinarias en Argentina, Brasil, Cuba, México y Nicaragua; en los otros países puede ser tanto a leyes, como a reformas constitucionales. Además, en Bolivia, Colombia, Ecuador y Venezuela, se contempla la iniciativa legislativa popular directa, donde dicha iniciativa puede ser aprobada o rechazada por los ciudadanos en consulta vinculante, contemplándose también la abrogación total o parcial de leyes por este mecanismo.

Revocatoria de mandato de los elegidos popularmente: puede ser de nivel nacional o nivel subnacional y la decisión de la revocatoria radica en el pueblo, a través de una consulta popular, seis países contemplan este MDD: Bolivia, Colombia, Ecuador, Panamá, Perú y Venezuela. Aunque este procedimiento pudiera parecer un proceso traumático para la vida política, es un ejercicio de la soberanía del pueblo y trae como consecuencia inmediata un mejor comportamiento del representante electo al estar sometido a control permanente por parte de los electores, fortaleciendo con ello la democracia.

Control Social del Estado: la transparencia y la rendición de cuentas son elementos intrínsecos de la democracia, y el control de las actuaciones del Estado por medio de las y los ciudadanos atiende al interés general antes que al interés particular. No se enmarca solamente en la lucha contra la corrupción, sino también, en una democracia más efectiva y funcional, más participativa. El control de las actuaciones de las instituciones y funcionarios del Estado por parte de la ciudadanía es una preocupación en las Constituciones de: Bolivia, Colombia, Ecuador, México, Nicaragua y Venezuela.

Planificación y elaboración de políticas públicas con participación vinculante: este mecanismo está desarrollado en las Constituciones de Bolivia, Colombia, Ecuador, México, Nicaragua y Venezuela, donde existen diversas formas de participación popular vinculante, con la participación protagónica de la población. Desde mi propia experiencia, cuando la población organizada desde la familia y la comunidad, participan protagónicamente en la planificación, ejecución y control de las políticas nacionales y locales, éstas se ejecutan con mayor celeridad, eficiencia y efectividad.

Como conclusión personal, diré que los mecanismos de democracia directa se irán perfeccionando en cuanto a sus formas de aplicación y en cuanto a sus objetivos, y se irán profundizando cada vez más, no percibo un retroceso en la existencia de ellos, lo que sí no puedo asegurar es cuál será el límite de actuación en el futuro y su afectación sensible a la democracia representativa. 


\section{La democracia en Nicaragua}

\section{VI.1. Los modelos democráticos en el constitucionalismo nicaragüense}

En Nicaragua, desde la Constitución de 1824, hasta la Constitución de 1974 y su posterior reforma de 1978, el sistema democrático constitucional era de una democracia representativa, con las variaciones históricas que hemos referenciado con anterioridad en este tipo de democracia en el mundo. La democracia de los propietarios con un sistema censitario, las elecciones indirectas y el Estado confesional, se manifiestan a partir de la Constitución de 1824 hasta la de 1893. Las mujeres adquirieron plenos derechos políticos, de elegir y ser elegidas, hasta en la reforma de 1955, ejerciendo por primera vez este derecho en la elección de 1957.

El régimen democrático representativo en Nicaragua estuvo afectado por la intervención de tropas norteamericanas en el territorio nacional de 1912 a 1925, y de 1927 a 1933, períodos en los que los intervencionistas elaboraron las leyes electorales, realizaban y supervisaban los procesos electivos.

Desde el primero de enero de 1937, al 19 de julio de 1979, el régimen de la dinastía de los Somoza controló el sistema político de Nicaragua desde la jefatura de la Guardia Nacional, controlando la implementación y los resultados de los sufragios en una aparente democracia representativa.

En el período del ejercicio exclusivo de la democracia representativa, comprendido de la Independencia de Nicaragua en 1821, hasta la Revolución del 19 de julio de 1979, las reglas y principios de dicha democracia no fueron generalmente observadas en dicho período, no hubo ni un solo cambio en el gobierno de partidos políticos u opción electoral diferente por medio de sufragio, sino que todos los cambios fueron por medio de las armas -Golpes de Estado, Guerras Nacionales, Guerras Civiles-; vale la pena destacar que el primer Golpe de Estado en la Historia Constitucional Democrática Nicaragüense se da en contra del primer Jefe de Gobierno de Nicaragua, Manuel Antonio de la Cerda, justamente por su Vice Jefe, Juan Argüello, quienes habían sido elegidos como consecuencia del primer sufragio popular, dando inicio al período de gobiernos democráticos representativos ${ }^{22}$. Fue hasta en la elección de 1990 que se cambia el partido político del gobierno por sufragio, ganando la candidata de la oposición, quien asumiría el nuevo período presidencial; igual situación se repetiría en la elección del 2006. En este período de democracia representativa, tampoco existió un pluralismo político, estableciéndose únicamente el bipartidismo y en algunas elecciones, como las de Zelaya, y la de 1937 con la candidatura de Anastasio Somoza García, únicamente hubo un candidato presidencial; fue hasta en las elecciones de 1984, que se establece el pluralismo político electoral. Y en las Constituciones de 1950 y 1974 se restringe la participación política a los partidos pertenecientes a internacionales, prohibiendo la conformación legal de partidos socialistas y partidos comunistas.

\footnotetext{
${ }^{22}$ Esgueva Gómez, Antonio (1994), Las Constituciones Políticas y sus reformas en la historia de Nicaragua, T. I y II. Editorial EL PARLAMENTO, Asamblea Nacional de Nicaragua, Managua.
} 


\section{VI.2. Los MDD en la vigente Constitución}

Sin ninguna duda, es la Constitución de 1987 la que introduce mecanismos de democracia directa en Nicaragua y el ejercicio de la soberanía popular de forma directa y a través de los representantes debidamente elegidos.

En la Constitución Política de la República de Nicaragua vigente aparecen diversos mecanismos de democracia directa y se establece la coexistencia de la democracia directa con la democracia representativa; constituyendo un Estado Democrático y Social de Derecho, donde la democracia se ejerce de forma directa, participativa y representativa y se establece como derecho constitucional de las y los ciudadanos en la formulación, ejecución, evaluación y seguimiento de las políticas públicas, estableciendo que debe legislarse para garantizar la participación efectiva nacional y localmente de la persona, la familia y la comunidad, siendo éstos elementos protagónicos del Plan de Desarrollo Humano de la Nación.

En el artículo 2, se establece el referéndum y el plebiscito como forma directa del ejercicio de la soberanía del pueblo. El plebiscito como consulta popular sobre decisiones que, dentro de sus facultades, dicte el Poder Ejecutivo y el referéndum es la consulta popular de leyes y reformas de las mismas, de carácter ordinario o constitucional, para su ratificación. Estos mecanismos pueden ser de invocación popular con cincuenta mil firmas de ciudadanas y ciudadanos; ambos MDD se aprueban en la Asamblea Nacional y es el Consejo Supremo Electoral el órgano responsable de su realización. Hasta la fecha, no se ha realizado ningún plebiscito ni referéndum en Nicaragua y no hay claridad normativa sobre el carácter vinculante o no de dichas consultas. A mi criterio, debería quedar claramente establecido en la Ley el carácter vinculante de sus resultados.

Existe la iniciativa legislativa popular para leyes ordinarias con el respaldo de no menos de cinco mil firmas de ciudadanos y ciudadanas, que recibe igual tratamiento que cualquier otra iniciativa legislativa proveniente de los demás autorizados constitucionalmente. Se exceptúan de la ILP las leyes orgánicas, tributarias, de carácter internacional, las de amnistía e indulto, y las reformas constitucionales. En once años de existencia constitucional, se ha utilizado doce veces este mecanismo.

En Nicaragua no existe, ni ha existido nunca en las constituciones históricas, la revocatoria de mandato, de manera pues que no existe experiencia práctica o normativa de este modelo de democracia directa.

En el artículo 50 de la Constitución Política de Nicaragua se establece que los ciudadanos tienen derecho a participar en igualdad de condiciones en los asuntos públicos y en la gestión estatal; en la formulación, ejecución, evaluación, control y seguimiento de las políticas públicas y sociales; estableciéndose en ello el control social del Estado. Sustentado en este artículo, y en los artículos 6, 52, 70 y 131 constitucionales y de conformidad a sus facultades establecidas en la Constitución, la Contraloría General de la República establece una Dirección de Denuncias Ciudadanas. Sin embargo, en la Ley Orgánica de la Contraloría General de la República, no se hace ninguna referencia al control social, pero es justo reconocer que cada día más ciudadanos y ciudadanas acuden a la Dirección de Denuncias Ciudadanas de la CGR.

La planificación y elaboración de políticas públicas con participación popular vinculante es el mecanismo de democracia directa que más se aplica en la actualidad en Nicaragua, siendo los artículos 2, 6 y $50 \mathrm{Cn}$ la base general para ello. Dentro de estos mecanismos podemos mencionar al Consejo Nacional de Planificación Económica y Social (CONPES), los Consejos y Gabinetes del Poder Ciudadano, los Gabinetes de la Familia, la Comunidad y la Vida, el Modelo de Alianza, Diálogo y Consenso entre el sector empresarial y los trabajadores con el go- 
bierno, los Consejos Nacionales Sectoriales (carne, café, arroz, lácteos, productos perecederos, cuero, calzado, pequeña y mediana empresa, entre otros), los Comités de Desarrollo municipales, los cabildos municipales y cabildos municipales ampliados, elaboración de presupuestos participativos municipales, los Gabinetes Comunitarios de Seguridad y Vida, entre otros.

En Nicaragua existe y se profundiza cada día más una cultura de participación ciudadana, en la elaboración, gestión, ejecución y control de políticas nacionales y locales, sin embargo, considero que se debe hacer un esfuerzo para ordenar mejor estos mecanismos de democracia directa y democracia participativa en el sistema normativo nacional.

\section{Resultados y aportes}

Estamos en una época de globalización, en un mundo tecnológicamente globalizado, donde nos desplazamos de un mundo de certezas hacia un mundo de nuevos e inciertos desafíos. En la actualidad, estamos llegando a un concepto diferente de la realidad, el concepto de un mundo en construcción y cambios permanentes. Esta nueva concepción del mundo y de la realidad nos genera más inseguridades, donde lo único cierto es lo incierto, la razón no está obligadamente asociada a la certeza, pero tampoco a la ignorancia, hay una búsqueda constante de la verdad, de verdades conceptuales, o al menos, una aproximación de la misma.

El concepto de democracia ha tenido una diversidad de criterios históricos cambiantes desde la génesis del Estado Constitucional Moderno en el siglo XVIII hasta la segunda década del siglo XXI; dichos términos no están universalmente unificados ni en sus conceptos, ni en sus contenidos, ni en sus alcances, ni en sus límites, proliferando una variedad de criterios. La democracia es un concepto que ha variado y cambiado en el transcurso del tiempo, y tiene diversas aplicaciones de conformidad a la realidad política concreta.

Para este trabajo investigativo, he tratado de conceptualizar democracia representativa, democracia participativa y democracia directa, sin pretender ser un axioma acabado, pero sí una necesaria y obligatoria aproximación.

La democracia representativa o democracia electoral es una forma de gobierno caracterizada por el rol de las elecciones como único fenómeno del ejercicio democrático, cuidando claramente la calidad de las mismas, que deben ser sin violencia, sin fraude, sin chantajes, sin prebendas, sin presiones, sin proscripciones, sin exclusiones y sin límites de ninguna naturaleza. Este tipo de democracia electoral representativa está cimentada, fundamentalmente, en el sufragio libre, universal, transparente, informado, con amplio respeto a los derechos políticos de los ciudadanos, correspondiendo a una concepción procedimental que Bobbio le denominó democracia minimalista, refiriéndose a las condiciones mínimas indispensables para el ejercicio democrático. El ejercicio del gobierno se realiza a través de los representantes electos por los ciudadanos, siendo la participación de estos últimos únicamente en los sufragios. Este tipo de régimen democrático se volvió el clásico en los siglos XVIII, XIX y XX, y sobrevive hasta nuestros días, sufriendo desde finales del siglo pasado y en la actualidad, duras críticas por sus objetivos incumplidos y consecuencia de ellos son los cambios que en la actualidad se proponen.

El concepto de democracia participativa, dotado de sustantividad propia, aparece en el campo del Derecho Constitucional y de la ciencia política en la segunda mitad del siglo XX; surge del seno de la misma democracia representativa, que da lugar a presiones populares para cambios políticos, conllevando el nacimiento de la democracia participativa, tal y como se entiende en la actualidad; sin embargo, no podemos negar que tiene su antecedente inmediato en la democracia directa. La democracia participativa se afirma en la actualidad como un modo 
de moderación y control sobre los representantes, que se materializa a través de comunidades organizadas, quienes intentan influir de diversas formas para que una determinada política pública sea adoptada o no; presupone un proceso de crecimiento de la responsabilidad política de la población, en la medida en que ésta participa e influye en las decisiones que afecta el modus vivendi. Surge como mecanismo de rescate a una criticada y deteriorada democracia representativa; la participación del ciudadano es eventual y puntual y se establece con mayor determinación como una participación consultiva; se entiende que en la democracia participativa las decisiones en última instancia son tomadas por los representantes elegidos democráticamente, mismas que son influenciadas por los electores organizados a través de diversas maneras.

Como concepto en esta investigación, se entiende por democracia directa en la actualidad, aquélla en la que las decisiones son tomadas por las y los ciudadanos, acompañados de los representantes electos democráticamente, siendo estos últimos los que mantienen la responsabilidad de la ejecución de las medidas, bajo la auditoría de los primeros, a través de diversos mecanismos o formas de organización.

El modelo de democracia formal representativo es ineficiente; los ciudadanos no se conforman con ser simplemente convocados periódicamente para elegir a sus representantes. Frente a la crisis de los regímenes democráticos representativos, se establecen mecanismos de democracia participativa y mecanismos de democracia directa como una forma de ejercer y valorar la ciudadanía, dando el paso de una democracia electoral, a una democracia de ciudadanía. En casi todos los países de América Latina, existen mecanismos de democracia participativa y mecanismos de democracia directa, con variadas concepciones vinculantes, incorporándolo en las Constituciones, normas legales, políticas nacionales y prácticas políticas. Los MDD constituyen una búsqueda de solución a la crisis de la democracia.

Desde México hasta Argentina, se registran novedosos mecanismos de democracia directa, aunque bajo formatos disímiles, intensidades diversas y resultados heterogéneos de la participación. De diecinueve Constituciones analizadas, todas contemplan mecanismos de democracia directa. Los países donde existen mecanismos de democracia directa en sus normativas constitucionales son: Argentina, Bolivia, Brasil, Chile, Colombia, Costa Rica, Cuba, Ecuador, El Salvador, Guatemala, Honduras, México, Nicaragua, Panamá, Paraguay, Perú, República Dominicana, Uruguay y Venezuela.

En Nicaragua, desde la Constitución de 1824, hasta la Constitución de 1974 y su posterior reforma de 1978, el sistema democrático constitucional era de una democracia representativa, con las variaciones históricas que hemos referenciado con anterioridad en este tipo de democracia en el mundo. La democracia de los propietarios con un sistema censitario, las elecciones indirectas y el Estado confesional, se manifiestan a partir de la Constitución de 1824 hasta la de 1893. Las mujeres adquirieron plenos derechos políticos, de elegir y ser elegidas, hasta en la reforma de 1955, ejerciendo por primera vez este derecho en la elección de 1957.

En la Constitución de 1987 comienzan a manifestarse mecanismos de democracia directa, que luego se profundizan en las sucesivas reformas producidas hasta hoy. Se habla pues de una democracia representativa, participativa y directa, con participación protagónica del individuo, familia y comunidad, y con un Modelo de Alianza, Diálogo y Consenso entre empresariado, trabajadores y Gobierno, para el desarrollo económico y social del país.

En los regímenes democráticos de la actualidad, los mecanismos de democracia directa y mecanismos de democracia participativa se establecieron para quedarse y no veo ningún indicio de retroceso en ello, por el contrario, una profundización y ampliación de los mismos. Dichos mecanismos vienen, indudablemente, a buscar la superación de la crisis de la democracia representativa y son coexistentes y no excluyentes. Parafraseando a Jellinek, con lo que planteó 
hace más de un siglo atrás, ¿hasta dónde transformarán la democracia y la organización del Estado estos mecanismos, afectando sensiblemente la democracia representativa? Es una respuesta que, probablemente, sólo mis hijos o mis nietos la sabrán.

\section{Referencias Bibliográficas}

Aristóteles (2005), Política, traducción de Julián Marías y María Araujo, Centro de estudios políticos y constitucionales, Madrid.

Boвbio, Norberto (1986), El futuro de la democracia, Fondo de Cultura Económica, México.

CARpizo, Jorge (2007), "Concepto de democracia y sistema de gobierno en América Latina”, en: Boletín mexicano de Derecho Comparado, Instituto de investigaciones jurídicas de la UNAM, nueva serie, año XL, núm.119, pp. 325-384.

Esgueva Gómez, Antonio (1994), Las Constituciones Políticas y sus reformas en la historia de Nicaragua, T. I y II. Editorial El parlamento, Asamblea Nacional de Nicaragua, Managua.

Hernández Valle, Rubén (2002), "De la democracia Representativa a la Democracia Participativa”, en: Anuario iberoamericano de justicia constitucional, núm. 6, pp. 199-219.

Jellinek, Georg (1991), Reforma y mutación de la Constitución, Centro de Estudios Constitucionales, Madrid.

Locke, John (2014), Ensayo sobre el gobierno civil, [en línea], disponible en: http://www.universidadabierta.edu.mx/Biblio/L/Ensayo\%2osobre\%2oel\%2ogob\%2ocivil.html, [consultado el 14 de febrero de 2014].

Montesquieu (1998), Del espíritu de las leyes, $12^{\circ}$ ed. Editorial Porrúa, México.

MoRín, Edgar (1990), Introducción al pensamiento complejo, Gedisa,Barcelona.

Murray, Santiago (2013), "La Democracia Representativa en el Sistema Interamericano”, en Democracia y representación en el Umbral del Siglo XXI. Memoria del III Congreso Internacional de Derecho Electoral, [en línea], disponible en: http://www.bibliojuridica. org/libros/1/238/23.pdf, [consultado el 23 de mayo].

Programa de las Naciones Unidas para el Desarrollo (PNUD) (2004), La democracia en América Latina. Hacia una democracia de ciudadanas y ciudadanos, Aguilar, Altea, Taurus, Alfaguara, Buenos Aires.

Rousseau, Jean-Jacques (1992), El Contrato Social. Editorial Guaymura, Tegucigalpa.

Secretaría Nacionalde Planificación y Desarrollo (2011), Tendencias de participación ciudadana en Ecuador, Senplades, Quito.

Subirat Humet, Joan (2012), Parlamento y políticas públicas. Conferencia magistral en la Maestría de Derecho Parlamentario realizada en el salón Rúben Darío de la Asamblea Nacional de Nicaragua, Managua, 25 de julio. 
Welp. Yanina (2008), Participación ciudadana y nuevas tecnologías en América Latina, en A. Lissidini, Y. Welp \& D. Zovatto (coords.), Democracia directa en Latinoamérica, Prometeo Libros, Buenos Aires, pp. 71-96.

Zovatto, Daniel (2008), Las instituciones de democracia directa a nivel nacional en América Latina, Balance comparado: 1978-2007, en A. Lissidini, Y. Welp \& D. Zovatto (coords.), Democracia Directa en América Latina, Prometeo Libros, Buenos Aires, Argentina, pp. 253-296.

\section{Lista de normas jurídicas}

Constitución de la Nación Argentina del 22 de agosto del año 1994.

Constitución del Estado Plurinacional de Bolivia del o7 de febrero del año 2009.

Constituição da República Federativa do Brasil. Texto constitucional promulgado em 5 de outubro de 1988, com as alterações adotadas pelas Emendas Constitucionais nos 1/1992 a 68/2011, pelo Decreto Legislativo no 186/2008 e pelas Emendas Constitucionais de Revisão nos 1 a $6 / 1994$.

Constitución Política de la República de Chile del 24 de octubre del año 1980 con sus reformas en texto actualizado hasta mayo de 2014.

Constitución Política de Colombia del 20 de julio del año 1991 hasta la reforma del 2007.

Constitución Política de la República de Costa Rica del o7 de noviembre de 1949, con sus reformas hasta el año 2003.

Constitución de la República Cuba del 24 de febrero de 1976, hasta la reforma del 31 de enero de 2003.

Constitución de la República del Ecuador del 20 de octubre de 2008, con su reforma del 13 de julio de 2011.

Constitución Política de la República de El Salvador del 20 de diciembre de 1983, con sus modificaciones hasta el 12 de junio de 2014.

Constitución Política de la República de Guatemala del 3 de junio de 1985, con su reforma del 17 de noviembre de 1993.

Constitución Política de la República de Honduras del 20 de enero de 1982, con sus reformas hasta 2005.

Constitución Política de los Estados Unidos Mexicanos del 05 de febrero de 1917, con sus reformas hasta la del 27 de mayo de 2015.

Constitución Política del Estado de Nicaragua del o8 de abril de 1826.

Constitución Política del Estado de Nicaragua del 12 de noviembre de 1838. 
Constitución Política de la República de Nicaragua del 19 de agosto de 1858.

Constitución Política de la República de Nicaragua, "La Libérrima" del 10 de diciembre de 1893.

Constitución Política de Nicaragua del 30 de marzo de 1905.

Constitución Política de la República de Nicaragua del 21 de diciembre de 1911.

Constitución Política de la República de Nicaragua del 22 de marzo de 1939.

Constitución Política de la República de Nicaragua del 22 de enero de 1948.

Constitución Política de la República de Nicaragua del o1 de noviembre de 1950.

Reforma de la Constitución Política de la República de Nicaragua de 1950, del 20 de abril de 1955 .

Constitución Política de la República de Nicaragua del 13 de abril de 1974.

Estatuto Fundamental del Gobierno de Reconstrucción Nacional de 20 de julio de 1979.

Estatuto sobre Derechos y Garantías de los Nicaragüenses del 21 de agosto de 1979.

Constitución Política de la República de Nicaragua del og de enero de 1987.

Ley de Reforma Constitucional a la Constitución de 1987 aprobada el 20 de enero de 1990 y publicada en La Gaceta, Diario Oficial N ${ }^{\circ} 46$ del o6 de marzo de 1990.

Ley $\mathrm{N}^{\circ} 192$, Ley de Reforma Parcial a la Constitución Política de la República de Nicaragua de 1987, publicada en La Gaceta, Diario Oficial N ${ }^{\circ} 124$ del 04 de julio de 1995.

Ley $\mathrm{N}^{\circ}$ 330, Ley de Reforma Parcial a la Constitución Política de la República de Nicaragua de 1987, publicada en La Gaceta, Diario Oficial N ${ }^{\circ} 13$ del 19 de enero del 2000.

Ley $\mathrm{N}^{\circ} 490$, Ley que reforma parcialmente el artículo 138, inciso 12 Constitucional de la Constitución Política de la República de Nicaragua de 1987, publicada en La Gaceta, Diario Oficial $\mathrm{N}^{\circ} 132$ del o7 de julio del año 2004 .

Ley ${ }^{\circ} 520$, Ley de Reforma Parcial a la Constitución Política de la República de Nicaragua de 1987, publicada en La Gaceta, Diario Oficial N ${ }^{\circ} 35$ del 18 de febrero de 2005.

Ley $\mathrm{N}^{\circ} 521$, Ley de Reforma Parcial al artículo 140 de la Constitución Política de la República de Nicaragua de 1987, publicada en La Gaceta, Diario Oficial N ${ }^{\circ} 35$ del 18 de febrero de 2005.

Ley $\mathrm{N}^{\circ} 527$, Ley de Reforma Parcial a la Constitución Política de la República de Nicaragua de 1987, publicada en La Gaceta, Diario Oficial N 68 del o8 de abril de 2005. 
Ley $N^{\circ}$ 854, Ley de Reforma Parcial a la Constitución Política de la República de Nicaragua, aprobada el 29 de enero de 2014 y publicada en la Gaceta, Diario Oficial N²6, del 10 de febrero de 2014.

Constitución Política de la República de Nicaragua de 1987, con sus reformas incorporadas. Publicada en La Gaceta, Diario Oficial número 32, del 18 de febrero del mismo año.

Constitución Política de la República de Panamá del 11 de octubre de 1972, con sus reformas hasta la reforma del 24 de noviembre de 2004.

Constitución Política de la República de Paraguay del 20 de junio de 1992.

Constitución Política del Perú del o1 de enero de 1994, con sus reformas hasta la entrada en vigencia el año 2011.

Constitución de la República Dominicana, del 10 de julio de 2015.

Constitución de la República Oriental del Uruguay del 15 de febrero de 1967, hasta su última reforma del año 2004.

Constitución Política de la República Bolivariana de Venezuela del 30 de diciembre de 1999, con su enmienda aprobada el 15 de febrero de 2009. 